$19^{\text {th }}$ International Conference on Modelling and Applied Simulation

$17^{\text {th }}$ International Multidisciplinary Modeling \& Simulation Multiconference

ISSN 2724-0037 ISBN 978-88-85741-48-5 (C) 2020 The Authors.

DOI: $10.46354 /$ i3m.2020.mas.012

\title{
Proposals for Optimizing a Selected Traffic Hub in the City Brno
}

\section{Radek Dvoracek ${ }^{1}$ and Katerina Vichova ${ }^{1, *}$}

\author{
${ }^{1}$ Tomas Bata University in Zlín, Faculty of Logistics and Crisis Management, Studentské náměstí 1532, Uherské \\ Hradiště, 686 01, Czech Republic \\ *Corresponding author. Email address: kvichova@utb.cz
}

\begin{abstract}
This paper deals with the optimization of one of the most problematic intersections in the north of Brno, Czech Republic. Specifically, it is an optimization of the intersection of roads I / 43 and II / 150. The aim is to optimize the intersection in such a way as to ensure both the flow of traffic and, above all, the safety of traffic in these places. The results of this optimization are presented using images from the simulation in the PTV VISSIM program, which clearly shows the changes in traffic after various optimization solutions. The result is the selection of the best solution for an optimization. The paper is divided into several chapters. First, a literature search on the issue will be carried out. Secondly, the current state of the intersection will be presented. The central part of the work will follow the optimization of the intersection with the presentation of the results. These results will be presented in various options for choosing the best solution. Finally, recommendations will be proposed.
\end{abstract}

Keywords: intersection; optimalization; traffic; PTV VISSIM; traffic hub.

\section{Introduction}

Safety in the area of traffic plays an essential role in nowadays lives. Road transport infrastructure contains highways, roads, local roads, junctions, road bridges, road tunnels, and crossings with other transport means. (Dvorak et al., 2012) Critical infrastructure is a complex system whose disruption or failure results in a significant impact on state interests, i.e., territorial security, economy, and the population's basic needs. (Novotny, 2020) There are defines several infrastructure sectors, such as healthcare, economy, communications, transport, and so on. Its inclusion reflects the importance of transport in the modern world in 2008 into the European critical infrastructure sectors (EC 2008). Road transport currently has an irreplaceable role in the European transportation network. (Rehak, 2020) Transport infrastructure elements such as road and railway structures are used every day by more and more people, and disruption to ar failure of these elements would have a broad impact. This importance of these elements depends on the level of performance they provide, i.e., their traffic-carrying capacity and traffic intensity. (Partman et al., 2019)

Urban traffic congestion is a widespread phenomenon that significantly affects many aspects of the quality of life. (Rostami-Shahrbabali, 2020) There could be seen the increasing number of cars by the inhabitants in the Czech Republic and Europe. An increase in the fleet of cars increases traffic intensity. (Volkova et al., 2019) Modeling traffic using appropriate software represents an efficient method in the field of transport engineering. Currently, specialized software products are being used for traffic problem solutions (e.g., OmniTrans, PTV Vissim, and many others). (Dvorak et al., 2012)

Microsimulation programs are often used to assess the quality of traffic conditions. (Jie et al., 2011) Microscopic traffic simulation models, in contrast to

(C) 2020 The Authors. This article is an open access article distributed under the terms and conditions of the Creative Commons Attribution (CC BY-NC-ND) license (https://creativecommons.org/licenses/by-nc-nd/4.0/). 
macroscopic models, distinguish and trace every single vehicle and driver. (Korcek et al., 2011)

The aim of this paper is to simulate the selected traffic intersection in the city of Brno, Czech Republic. For this purpose, will be used traffic simulation software PTV Vissim.

\section{Methodology}

Several methods are used in this paper. It is a method of analysis, comparison, and simulation. First, the method of analysis is used, which is used to analyze the current state of the selected intersection in the city of Brno. The simulation method is also used. PTV Vissim software was used for simulations (further described below). Finally, a comparison method was used. This method is used to compare the result of simulations within the selected intersection.

As mentioned above, a simulation method using PTV Vissim software was used. There was used the student version of the software.

TV Vissim is most often used to evaluate proposals for transport infrastructure, traffic management proposals on the road, IDS analysis, and simulation benefits of telematics traffic management, public transport simulation, and so on. (Konfant, et al., 2017)

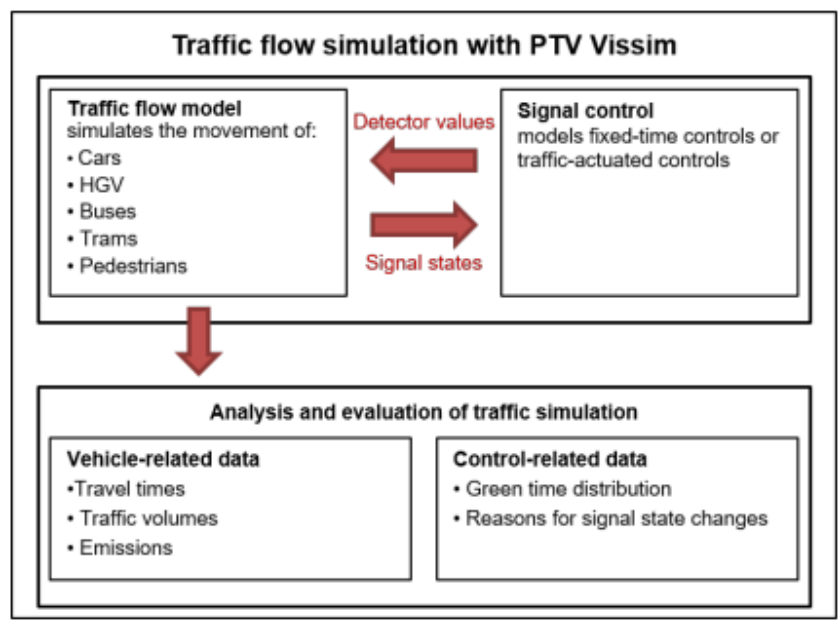

Figure 1. Traffic flow simulation with PTV Vissim (PTV Vissim 8, 2016)

The microscopic software PTV Vissim is specially designed for modeling multimodal transport flow, including cars, trucks, buses, rail vehicles, cyclists, and pedestrians (the essence of PTV Vissim is Wiedermann "car-following" model). (Ondrus et al., 2016)

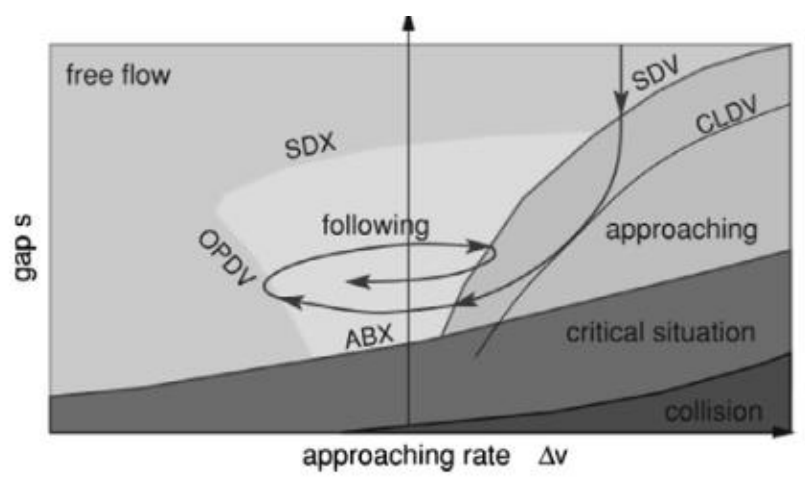

Figure 2. Wiedemann's car-following model. (Treiber et al., 2013)


Figure 3. Vehicle following phases. (Durrani et al., 2016)

Figure 3 shows the vehicle following phases. There could be five phases, from uninfluenced driving to stationary vehicles. Based on the type of the process, the simulation evaluates the length from the previous car.

\section{Current state of the solved intersection}

The crossroads addressed in this work is the intersection of roads I / 43 and II / 150 near the villages of Sebranice and Skalice nad Svitavou. This crossroads is a significant road point in the north of Brno, as it connects the road I / 43 leading from Brno to Svitavy with the road II / 150 leading to Prostějov.

The intersection is of the T type, with branch lanes 
being created on the I / 43 road from both directions, serving for a smooth connection to the II / 150 road. Road II / 150 leads to way I / 43 directly without continuous connecting lanes.

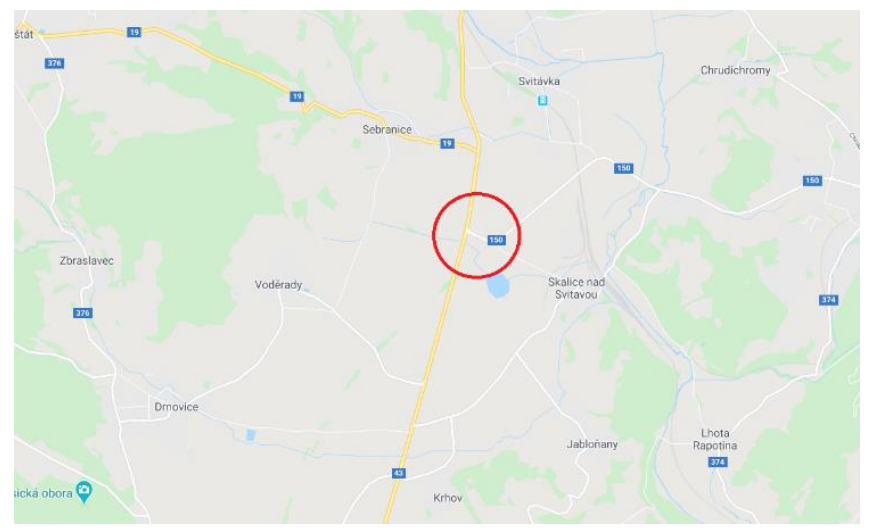

Figure 4. Map display

The road I / 43 is a Czech 1st class road leading from Brno via Svitavy, Lanškroun, and Králíky to Poland (direction Kladsko and Wrocław). It is $115.725 \mathrm{~km}$ long, and in the section Brno - Svitavy, the European road E461 runs along with it. The first part from Brno to the village of Česká is built as a directionally divided fourlane road and is referred to as the Svitavy Radial. [2]

Road II / 150 is the Czech road II. classes, leading from the Central Bohemian Region through the Vysočina Region, the South Moravian Region and the Olomouc Region to the Zlín Region. It passes through a total of 9 districts. The whole leads in the route formerly belonging to the road I / 18, it shares a large part of the road with the road I / 19 (section Havličkưv Brod - Boskovice), so it is divided into two separate sections (Votice - Havlíčkův Brod and Boskovice Valašské Meziříčí). The entire length of the road measures $206,232 \mathrm{~km}$. Together with the branches of roads II / 150A, II / 150B, II / 150H, and II / 150I, it measures $210,492 \mathrm{~km}$. Way II / 150 is the longest road II. class. [3]

The intersection of roads I / 43 and II / 150 is near the villages of Sebranice and Skalice nad Svitavou. This crossroads is a significant road point in the north of Brno, as it connects the road I / 43 leading from Brno to Svitavy with the road II / 150 leading to Prostějov.

The intersection is of the T type, with branch lanes being created on the I / 43 road from both directions, serving for a smooth connection to the II / 150 road. Road II / 150 leads to road I / 43 directly without continuous connecting lanes.

\section{Results}

In the following section, simulations of the I / 43 and II / 150 intersections are performed in the VISSIM program. First, a simulation of the current state is performed in order to be able to compare the optimized variants with it. After simulating the current state, designs and simulations of various optimization variants were performed.

\subsection{Simulation of the current state}

The software PTV Vissim simulated this intersection's current state using traffic census data from 2016, which are the most up-to-date data currently available. As traffic continues to increase, traffic data in the simulation have increased by about $10 \%$ to reflect the current situation accurately. The simulation showed that the traffic on the road I / 43 is relatively smooth, which in the author's opinion is caused by continuous turning lanes. However, columns may form at the exit of road II / 150, which is due to its direct exit to road I / 43 and, in fact, by the very nature of a T-junction.

However, the problem is not the flow of traffic, which is not entirely ideal, but mainly the safety of this intersection. Even though the view is not overshadowed and you can see in both directions several hundred meters away, there are numerous dangerous situations, including serious traffic accidents. These hazardous situations occur mainly due to the intersection's shape. Vehicles from road II / 150 connect directly from the minimum speed to road I / 43, where the rate is limited to $70 \mathrm{~km} \mathrm{/} \mathrm{h} \mathrm{at} \mathrm{the}$ intersection. It is for these reasons that this intersection has been optimized. Suggestions for optimization are given in the following chapters.

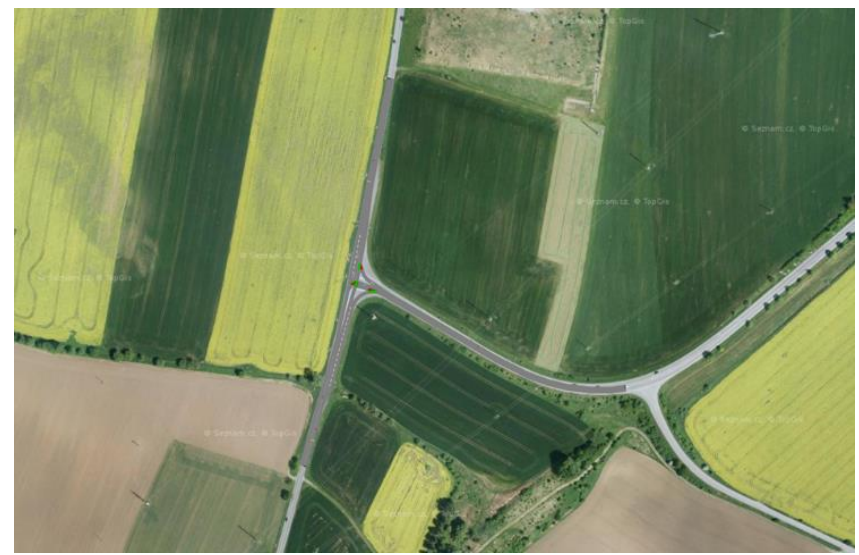

Figure 5. Current state without the simulation

The following figure shows a simulation of the current state of traffic at the intersection. 


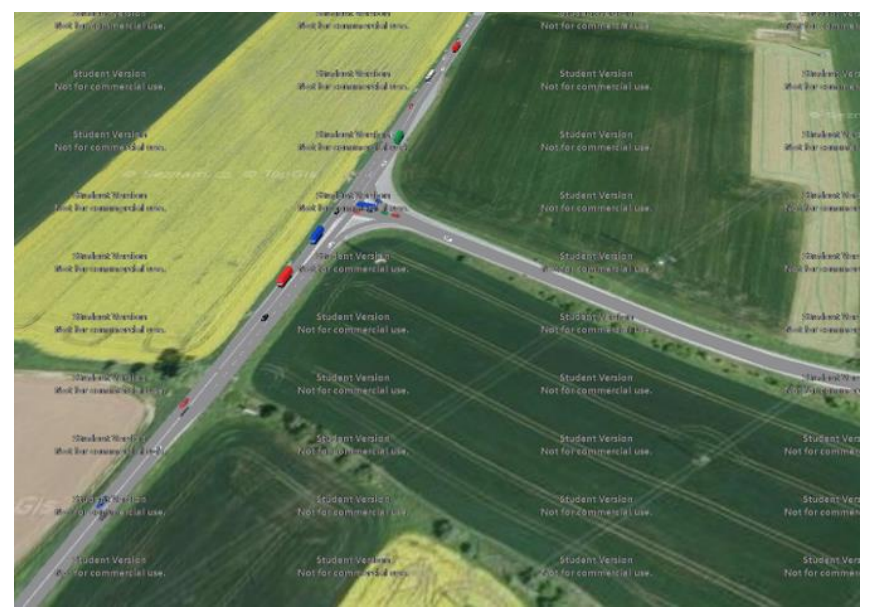

Figure 6. Simulation of the current state

\subsection{Simulation of the option no. 1}

In the first case of optimization, a simulation of a roundabout intersection was performed. This type was chosen about the high safety of this solution, which this solution meets, but the slowdown in traffic is severe. A similar roundabout is located on the I / 43 road just a few kilometers from the intersection, where it works relatively correctly.

During the simulation, it was found that traffic slowdown is drastic in this solution, and long columns are formed, which is unacceptable. This type of roundabout works relatively well a few kilometers away, but not at the intersection. It is the traffic density on the connected roads. At the roundabout mentioned above, the traffic density on the connected roads is half the intersection.

Below it is possible to see figure 7 from the simulation, which well shows potential changes in traffic by changing the intersection to a roundabout with a direct connection of roads.

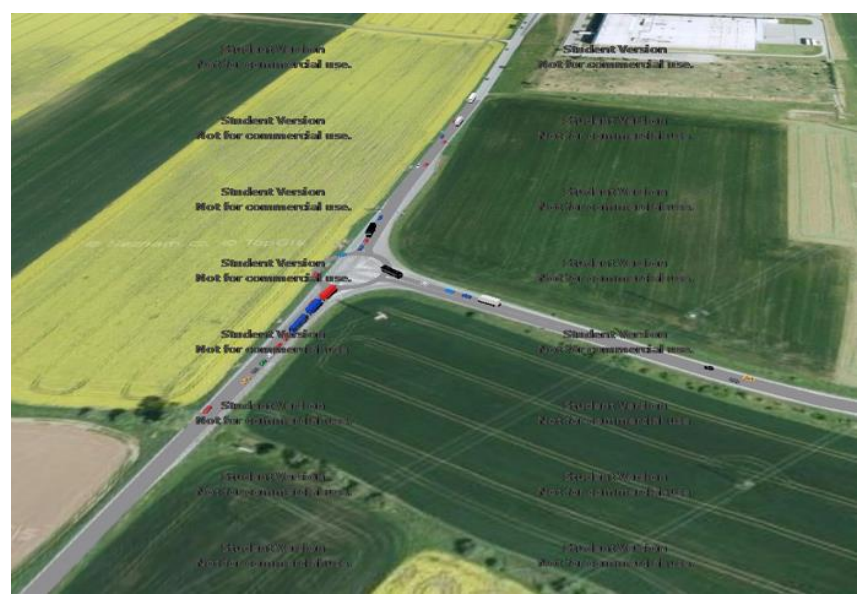

Figure 7. Simulation of the option no. 1

\subsection{Simulation of the option no. 2}

In the second case of optimization, a simulation of an intersection with a roundabout was performed. There a direct exit from the road I / 43 is proposed, in the direction Brno-Svitavy, to the road II / 150 and also a direct connection from the road II / 150 to the road I / 43 in the same direction.

According to the simulation, this roundabout solution seems to be much more suitable than the previous variant, but the traffic restriction is still relatively large. This restriction could be observed on both roads, but unlike the previous solution, such large columns do not form on the I / 43 road.

Below you can see figure 8 from the simulation, which well shows possible changes in traffic by changing the intersection to a roundabout with a continuous connection in the direction of BrnoSvitavy.

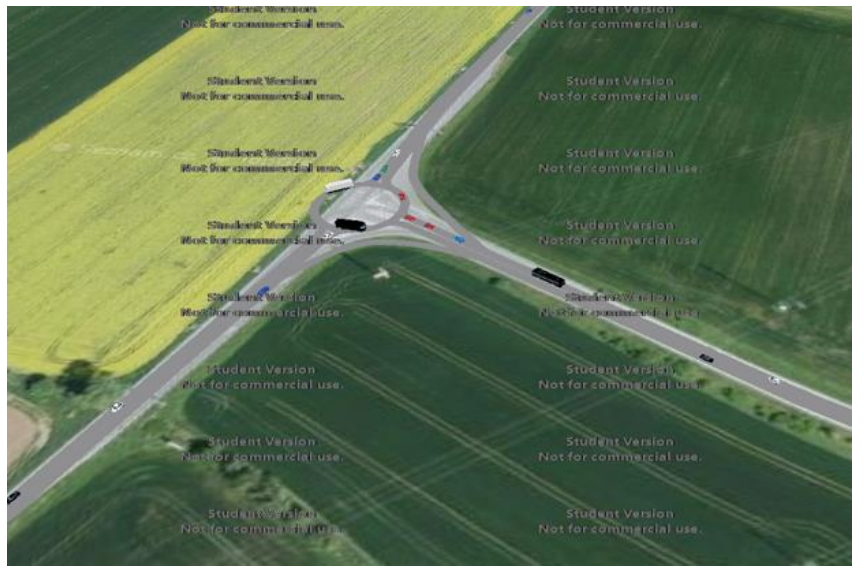

Figure 8. Simulation of the option no. 2

\subsection{Simulation of the option no. 3}

In the third case of optimization, a simulation of an intersection with a roundabout was performed, when a direct exit from the road I / 43 is proposed, in the direction Brno-Svitavy, to the road II / 150 and also a direct connection from the road II / 150 to the road I / 43 in the same direction, precisely as in the previous case, but besides, a direct connection of the road I / 43 in the direction of Svitavy-Brno was added.

In this case, there is already a relatively small effect on traffic density, as the main road, I / 43 in the direction of Svitavy-Brno is directly passable. Of all the proposed roundabout variants, it appears to be the most optimal, both from safety and, above all, from influencing traffic.

Below you can see pictures from the simulation that show possible changes in traffic by changing the intersection to a roundabout with a continuous connection in the direction of Brno-Svitavy and a direct connection in the direction of Svitavy-Brno. 


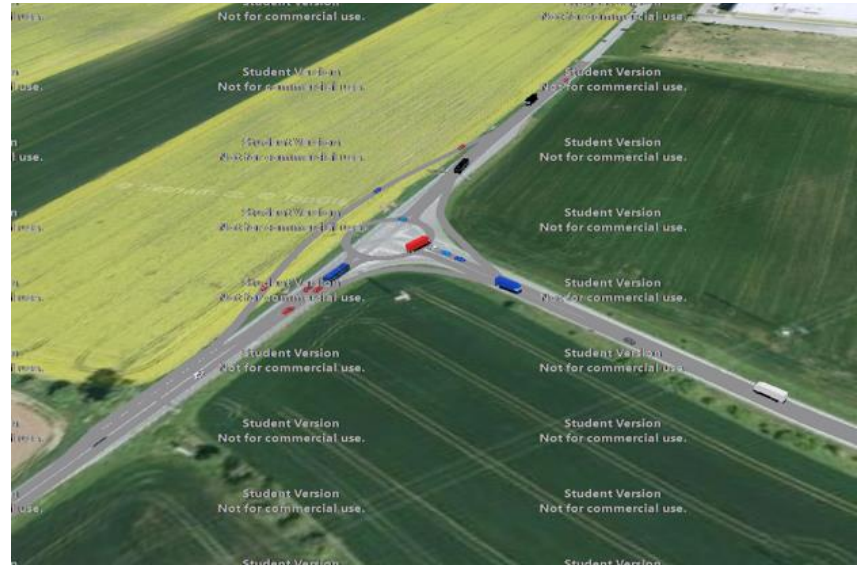

Figure 9. Simulation of the option no. 3

\subsection{Simulation of the option no. 4}

In the last case of optimization, the solution of the intersection I / 43 and II / 150 was proposed using an extra-level connection of these roads. In this case, the road I / 43 would be led on an elevated bridge structure, or the brought soil. Road II / 150 would remain at the same height, with the connection of individual ramps to and from road I / 43 being solved by a pillar structure.

During the simulation, it was found that this type of intersection would be the most suitable for the situation. The safety of this type of intersection is at a high level, and the impact on traffic is minimal. However, this solution is the least advantageous from an economic point of view, compared to the previous variants. It is considered whether it would be reasonable to implement this solution, as in these places, there should be a road D / R43, which would solve traffic problems in the region. However, the question is when will the construction of this road be started at all, because, since the end of the Second World War, nothing has been built from this road at all.

Below you can see pictures from the simulation which will show any changes in traffic by changing the intersection to a level crossing.

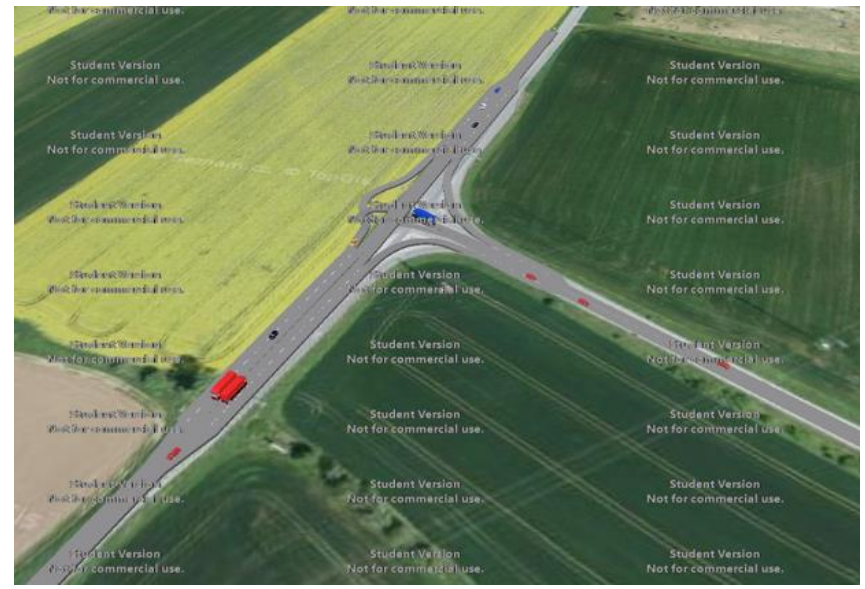

Figure 10. Simulation of the option no. 4

\section{Discussion}

The aim of this paper was to simulate the selected traffic intersection in the city of Brno, Czech Republic, for this purpose was used traffic simulation software PTV Vissim. The paper was divided into several parts. Firstly, there was a short literature review of the problem with the traffic. Secondly, there was described the methods which are used in the paper. There were used three methods. One of them is a simulation, where was used the software PTV Vissim. There was described as the primary Wiedermann car-following model. The central part of the paper resulted. This part into several sub-parts. There was simulated the current state of the intersection and several options of the solve.

Regardless of the economic side of things, the common suitable option would be to build a level crossing at the current intersection. Concerning the financial side of things and the possible future construction of the road D / R43, now more intended R43, the most suitable temporary solution would be to build a variant with a roundabout, where a direct exit from the road I / 43, in the direction Brno-Svitavy, to road II / 150 and also a direct connection from road II / 150 to the road I / 43 in the same direction. It is the variant of optimization number three. This variant is the second most suitable after the option by the level crossing, and it is not necessary to build an aboveground structure.

However, an ideal solution would be to build the D / $\mathrm{R} 43$ road as quickly as possible, at least in the four-lane expressway profile, as this would solve a lot of problems with the I / 43 road, which currently configures two lanes with four slopes, far from sufficient current traffic intensity. However, it is not clear when the inhabitants of this region will see a new road, as, since the end of the Second World War, practically nothing has happened from a construction point of view. For these reasons, it is desirable to continue to focus on dangerous places on the I / 43 road.

Road transport is an essential component of the European economy. However, this sector is responsible for the increase of emissions and fuel consumption from year to year. (Coelho et al., 2011) Based on the increased throughput at the intersections, we could decrease the emissions.

\section{Conclusions}

The paper solves the proposals for optimizing a selected traffic hub in the city Brno. The paper aimed to simulate the current state of the intersection and propose the option for the increased throughput and decreased emissions. In this paper was used the simulation software PTV Vissim. This part could be a gate in mind as the limit of this research. The simulation could be used by several other simulation software.

The paper tries to point out the current state of 
transport infrastructure elements. These elements have become insufficient over time. Based on the article, we want to point out these shortcomings focusing on one selected intersection and suggest possible solutions. Based on these measures, the flow of operations is increased, and thus emissions are reduced.

\section{Funding}

This research was supported by the Internal Grant Agency of Tomas Bata University in Zlín, under the project no. IGA/FLKR/2020/002.

\section{References}

Coelho, M. F., Coelho, J. M. (2011). Impact of Road Traffic Incidents on Pollutant Emissions. IEEE Forum on Integrated and Sustainable Transportation Systems, 312-316.

Durrani, U., Lee, Ch., Maoh, H. (2016). Calibrating the Wiedermann's vehicle following model using mixed vehicle-pair interactions. Transportation Research Part C: Emerging Technologies, 67: 227-242.

Dvorak, Z., Leitner, B., Novak, L. (2012). National Transport Information System in Slovakia as a Tool for Security Enhancing of Critical Accident Locations. Proceesings of $16^{\text {th }}$ International Conference. Transport Means. 2012, 145-148.

European Council. (2008) Council Directive $2008 / 114 /$ EC of 8 December 2008 on the Identification and Designation of European Critical Infrastructures and the Assessment of the Need to Improve their Protection.

Jie, L., Fungfung Z., Zuylen, H., Shoufeng, L. (2011). Calibration of a micro simulation program for Chinese city. Procedia Social and Behavioral Sciences, 20:263-272.

Konfant, M., Gogola, M. (2017). Possibilities of using traffic planning software in Bratislava. $12^{\text {th }}$ International Scientific Conference on Sustainable, Modern and Safe Trasnport (TRANSCOM 2017),433438.

Korcek, P., Sekanina, L., Fucik, O. (2011). A Scalable Cellular Automata Based Micrscopic Traffic Simulation. IEEE Intelligent Vehicles Symposium, IV: 13-18.

Novotny, P., Janosika, M. (2020) Designating Regional Elements System in a Critical Infrastructure System in the Context of the Czech Republic. Systems,8,13.

Ondrus, J., Cernicky, L. (2016). Usage of Polcam device for parameter monitoring and traffic flow modelling. Communications: Scientific letters of the University of Žilina, 18:118-123.

Partman, D., Splichalova, A., Rehak, D., Onderkova, V. (2019). Factors Influencing the Performance of Critical Land Transport Infrastructure Elements. $13^{\text {th }}$ International Scientific Conference on Sustainable, Modern and Safe Trasnport (TRANSCOM 2019), 15181524.

PTV Vissim 8, User Manual. (2016) PTV AG, Karlsruhe, Germany.

Rehak, D., Partmena, D., Brabcova, V., Dvorak, Z. (2020) Identifying Critical Elements of Road Infrastructure Using Cascading Impact Assessment. TRANSPORT.

Rostami-Shahrbabaki, M., Safavi A.A., Papageorgiou, M., Setoodeh, P., Papmichail, I. (2020) State estimation in urban traffic networks: A two-layer approach. Transportation Research Part C, 115:2-24.

Treiber, M., Kesting, A. (2013). Traffic Flow Dynamics: Data, Models, and Simulation. Springer.

Volkova, E., Stepanenko, A. (2019). Traffic intensity on highway R-255 Siberia in Irkutsk region. IOP Conf. Series: Materials Science and Enginnering, 667: 1-6. 